\title{
A Comparison Between AHP and Hybrid AHP for Mobile Based Culinary Recommendation System
}

\author{
https://doi.org/10.3991/ijim.v12i1.7561 \\ Ratih Kartika Dewi( $\left.{ }^{\bowtie}\right)$, Buce Trias Hanggara, Aryo Pinandito \\ Brawijaya University, Malang, Indonesia \\ ratihkartikad@ub.ac.id
}

\begin{abstract}
Mobile based culinary recommendation system has become critical topic in mobile application. Some methods presented in the literature propose the use of the AHP (Analytic Hierarchy Process), AHP TOPSIS (Technique for Order of Preference by Similarity to Ideal Solution) and fuzzy AHP for mobile based culinary recommendation system. However, there are no comparative studies of these three methods when applied to mobile based culinary recommendation system. Thus, this research presents a comparative analysis of these three methods in the context of culinary recommendation system in mobile environment. The comparison was made based on accuracy and time complexity because mobile application environment needs low time complexity. The results have shown that all of these methods are suitable for culinary recommendation system in mobile environment. Fuzzy AHP have the highest accuracy between all of these methods, it have $66,67 \%$ accuracy. But, AHP TOPSIS shows the best performance in time complexity, with order of growth in quadratic class $\left(\mathrm{n}^{2}\right)$.
\end{abstract}

Keywords - culinary recommendation, mobile application, AHP, AHP TOPSIS, Fuzzy AHP.

\section{$1 \quad$ Introduction}

When visiting foreign place, difficulty in choosing where to eat can be solved by asking suggestions for tourism guides. However, tourism guide doesn't know everyone favorite taste and environment. Thus, mobile based culinary recommendation system is very required. Some methods presented in the literature propose the use of the AHP (Analytic Hierarchy Process) [1], AHP TOPSIS (Technique for Order of Preference by Similarity to Ideal Solution)[2, 3] and fuzzy AHP [4] for mobile based culinary recommendation system.

However, there are no comparative studies of these three methods when applied to mobile based culinary recommendation system. Thus, this research presents a comparative analysis of these three methods in the context of mobile based culinary recommendation system in Malang, Indonesia. The comparison was made based on accuracy and time complexity because mobile application environment needs low time complexity. 
Algorithm complexity can be divided in time and space complexity, time complexity is measured by the number of basic operation executed as a function of input size (n). Space complexity is measured by the memory used to execute the algorithm [5]. In mobile environment time complexity has become critical topic.

AHP is a leading approach in multi criteria decision making [6]. Two main issues in AHP are rank consistency and time complexity in a complex decision making problem such as large number of decision alternatives [7]. AHP has limitation in time complexity because as the levels of hierarchy increase, it takes time to process AHP calculation [6].

Time complexity of AHP is in O $\left(\min \left\{\mathrm{mn}^{2}, \mathrm{~m}^{2} \mathrm{n},\right\}\right)$ time [7], where $\mathrm{m}$ is alternatives and $\mathrm{n}$ is criteria. AHP also has rank reversal problem when criteria or alternatives are added or deleted from database [6]. Rank consistency in AHP depends on pairwise comparison matrix and matrix size [7]. According to [8,9], it suggests that the number of criteria or alternative in AHP is limited to nine. Despite the limitations, AHP is simple to apply and it is a leading approach in multi criteria decision making [6].

Culinary recommendation System using AHP [1] have limitations on accuracy value. It has $30 \%$ accuracy. So, in [4] AHP is combined with fuzzy as attribute weighting. With fuzzy as alternative of attribute weighting, the value of accuracy increase until $66,67 \%$.

Another method for culinary recommendation system is AHP TOPSIS. TOPSIS that combined with AHP have a purpose for minimizing time complexity. According to [10] TOPSIS has the fewest rank reversals among others method compared, such as ELECTRE, TOPSIS, Multiplicative Exponential Weighting (MEW), SAW and AHP. In addition, TOPSIS has high flexibility and can accommodate group decision making for further extension [11]. TOPSIS has lower time complexity than AHP.

Time complexity of TOPSIS can be divided in 3 stages, complexity of attribute normalization and weighting is in $\mathrm{O} \mathrm{n}^{2}$. Whereas the complexity of positive-negative ideal solution and $\mathrm{V}$ distance is in $\mathrm{O} \mathrm{n}$ and the algorithm ranking results is in $\mathrm{O} 1$ [11]. Attribute weighting in TOPSIS has high subjectivity because decision maker can gives weight for attributes directly, without regarding the consistency of the weight value. Because of that reason, TOPSIS is combined with AHP. Attribute weighting can be done with AHP and recommendation ranking can be done with TOPSIS. In this research we also use AHP TOPSIS for culinary recommendation system in Malang, as has been done in [3], and analyze the accuracy and time complexity.

The reminder of this research is organized as follows. In section 2 to 4 , a review of AHP, Fuzzy AHP, and AHP TOPSIS are presented. The result and analysis is described in Section 6 and we draw our conclusion in the last section.

\section{AHP (Analytic Hierarchy Process)}

The Analytic Hierarchy Process (AHP) is a general theory of measurement, which is used to derive ratio scales from both discrete and continuous pairwise comparisons [1]. It is the form of decision-making method as well. The comparisons can be taken 
from actual measurements or by using a fundamental scale which reflects the relative strength of personal preferences and feelings. As shown in figure 1, for an example of AHP hirarchies consider a decision problem with a goal to be reached, three alternative ways of reaching the goal, and three criteria against which the alternatives need to be measured. Such a hierarchy can be visualized as a diagram like the one immediately below, with the goal at the top, the three alternatives at the bottom, and the three criteria in between.

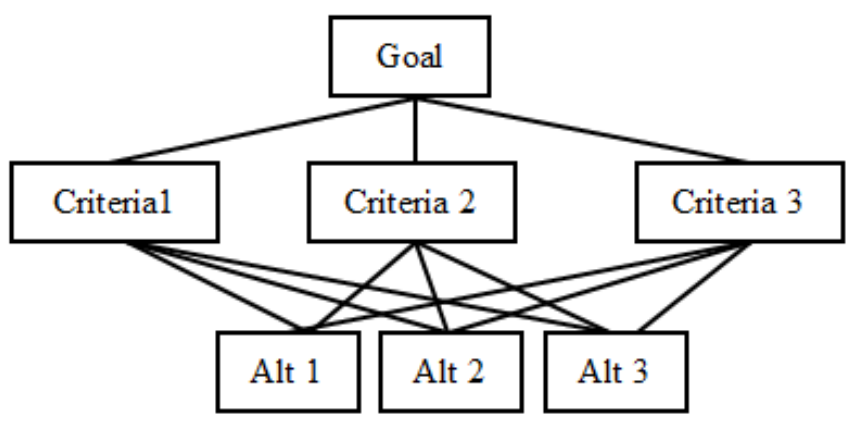

Fig. 1. Visualization of AHP Hierarchies

The best approach to determine the rank of criterion in a pairwise comparison, is using the calculation of Eigen Vector from the matrix represents a local priority scale to obtain the orderof priority or importance of criterions and alternatives [9].

\section{Fuzzy AHP}

Fuzzy-AHP is a ranking method that embeds the fuzzy theory to basic AHP $[8,9]$. This method systematically solves the selection problem that uses the concepts of fuzzy set theory and hierarchical structure analysis. Basically, Fuzzy AHP handles weaknesses that contained in AHP, problems with criteria that have more subjective properties.

AHP is a widely used decision making tool in various multi-criteria decision making problems. In general AHP model, the objective is in the first level, the criteria and subcriteria are in the second and third levels respectively. Since basic AHP does not include vagueness for personal judgments, it has been improved by benefiting from fuzzy logic approach [4].

In Fuzzy-AHP, the pair wise comparisons of both criteria and the alternatives are performed through the linguistic variables, which are represented by triangular numbers [12]. Linguistic variables take on values defined in its term set: its set of linguistic terms. Linguistic terms are subjective categories for the linguistic variable. A linguistic variable is a variable whose values are words or sentences in a natural or artificial language. The triangle fuzzy scale used here can be seen in Table 1 below. 
Table 1. Linguistic Terms and the Corresponding Triangular Fuzzy Number

\begin{tabular}{|c|c|c|}
\hline Scale & Linguistic & Fuzzy Triangular Scale \\
\hline 1 & Equally important & $(1,1,1)$ \\
\hline 3 & Weakly important & $(2,3,4)$ \\
\hline 5 & Fairly important & $(4,5,6)$ \\
\hline 7 & Strongly important & $(6,7,8)$ \\
\hline 9 & Absolutely important & $(9,9,9)$ \\
\hline 2 & & $(1,2,3)$ \\
\hline 4 & \multirow{2}{*}{ The intermittent values } & $(3,4,5)$ \\
\cline { 3 - 3 } \cline { 3 - 3 } & & $(5,6,7)$ \\
\hline 8 & & $(7,8,9)$ \\
\hline & & \\
\hline
\end{tabular}

According to the corresponding triangular fuzzy numbers of these linguistic terms, for example if the decision maker states "Criterion 1 (C1) is Weakly Important than Criterion 2 (C2)", then it takes the fuzzy triangular scale as $(2,3,4)$. On the contrary, in the pair wise contribution matrices of the criteria, comparison of $\mathrm{C} 2$ toC1 will take the fuzzy triangular scale as $(1 / 4,1 / 3,1 / 2)$.

\section{AHP TOPSIS (Technique for Order of Preference by Similarity to Ideal Solution)}

TOPSIS method is presented in 1981 Hwang and Yoon [13]. TOPSIS is a multiple criteria method to identify solutions from a finite set of alternatives. The basic principle is that the chosen alternative should have the shortest distance from the positive ideal solution and the farthest distance from the negative ideal solution.

The procedure of TOPSIS can be expressed in a series of steps:

1. Determine normalized decision matrix using Euclidean length of a vector method

$$
r_{i j}=\frac{x_{i j}}{\sqrt{\sum_{i=1}^{m} x^{2}{ }_{i j}}}
$$

where:

rij = result of normalized decision matrix R;

$\mathrm{i}=1,2,3, \ldots, \mathrm{m}$;

$\mathrm{j}=1,2,3, \ldots, \mathrm{m}$;

2. Determine weighted normalized decision matrix with weight $\mathrm{W}=(\mathrm{w} 1, \mathrm{w} 2, \ldots$, wn) 


$$
V=\left[\begin{array}{ccc}
w_{1} r_{11} & \square & w_{n} r_{1 n} \\
\square & \square & \square \\
w_{1} r_{m 1} & \square & w_{n} r_{m n}
\end{array}\right]
$$

where:

$\mathrm{i}=1,2,3, \ldots, \mathrm{m}$;

$\mathrm{j}=1,2,3, \ldots, \mathrm{m}$;

3. Determine the positive ideal and negative ideal solution

$$
\begin{aligned}
& A^{+}=\left\{\left(\max v_{i j} \mid j \in J\right) \quad\left(\min v_{i j} \mid j \in J\right), i=1,2,3, \ldots, m\right\}=\left\{v_{1}{ }^{+}, v_{2}{ }^{+}, \ldots, v_{m}{ }^{+}\right\} \\
& A^{+}=\left\{\left(\max v_{i j} \mid j \in J\right)\left(\min v_{i j} \mid j \in J^{\prime}\right), i=1,2,3, \ldots, m\right\}=\left\{v_{1}^{-}, v_{2}{ }^{-}, \ldots, v_{m}{ }^{-}\right\}
\end{aligned}
$$

4. Calculate the separation measures, using the n-dimensional Euclidean distance. The separation of each alternative from the ideal solution is given as

$$
S_{i}^{+}=\sqrt{\sum_{j=1}^{n}\left(v_{i j}-v_{j}^{+}\right)^{2}}, \mathrm{i}=1,2,3, \ldots, \mathrm{m} ;
$$

Similarly, the separation from the negative ideal solution is given

$$
S_{i}^{-}=\sqrt{\sum_{j=1}^{n}\left(v_{i j}-v_{j}^{-}\right)^{2}}, \mathrm{i}=1,2,3, \ldots, \mathrm{m} \text {; }
$$

5. Calculate the relative closeness to the ideal solution.

$$
C_{i}^{+}=\frac{S_{i}^{-}}{S_{i}^{-}+S_{i}^{+}}
$$

With $0<\mathrm{Ci}+<1$ and $\mathrm{i}=1,2,3, \ldots, \mathrm{m}$;

6. Rank the preference order. For ranking alternatives using index $\mathrm{Ci}+$, we can rank alternatives in decreasing order

\section{Comparative Analysis}

Comparative analysis was made based on accuracy and time complexity. It was because mobile application environment needs low time complexity.

\subsection{Accuracy}

Accuracy was tested in order to compare the amount of true data from overall data. Data tested in this paper were obtained from [1]. The amount of data are 30 data and test conducted in Malang, Indonesia. These data was tested with AHP[1], Fuzzy AHP[4] and AHP TOPSIS [3]. 
The results have shown that accuracy with AHP for culinary recommendation system is $30 \%$. Fuzzy AHP algorithm improve the accuracy of AHP from $30 \%$ to $66,67 \%$. This significant result was because Fuzzy improved weighting calculation in AHP. With AHP TOPSIS, accuracy is 40\%. It's better than original AHP, but the accuracy still below Fuzzy AHP. It was because AHP TOPSIS focused on lowering computational time complexity.

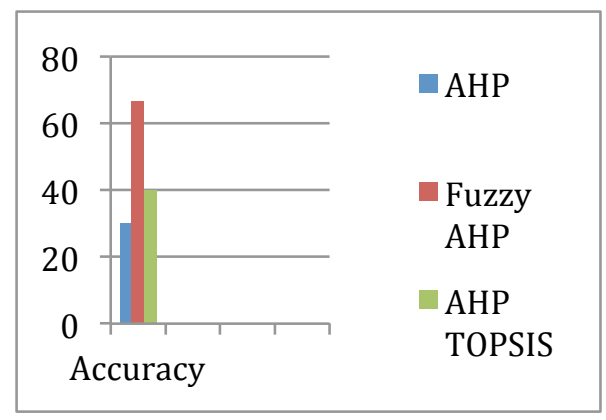

Fig. 2. Test of Accuracy

Figure 2 shown the test of accuracy in culinary recommendation system. From all the methods compared, Fuzzy AHP has the highest accuracy, 66,67\% and AHP has the lowest accuracy, $30 \%$.

\section{$5.2 \quad$ Time Complexity}

This paper also compare time complexity for all the methods. To compare time complexity for an algorithm, there is an reference called order of growth. Order of growth was chosen from the highest complexity between all order of growth's class $[5,14]$.

AHP and fuzzy AHP time complexity was previously calculated in [7] for AHP and [15] for fuzzy TOPSIS. For AHP TOPSIS algorithm this paper compute time complexity manually from AHP TOPSIS source code. Table 2 shows time complexity for each algorithm and also the order of growth.

Table 2. Time complexity of algorithm

\begin{tabular}{|c|c|c|}
\hline & Time complexity & order of growth's class \\
\hline AHP & $\operatorname{Min}\left(\left\{\mathrm{mn}^{2}, \mathrm{~m}^{2} \mathrm{n}\right\}\right) \in 0 m n^{2}$ & $m n^{2}$ \\
\hline Fuzzy AHP & $\mathrm{n}^{2}(\mathrm{~m}+1)+\mathrm{m}(7 \mathrm{n}+6) \in 0 m n^{2}$ & $m n^{2}$ \\
\hline AHP TOPSIS & $\mathrm{n}^{2}+2 \mathrm{n}+1+\mathrm{n}^{2}+1=2 \mathrm{n}^{2}+2 \mathrm{n}+2 \in 0 n^{2}$ & $n^{2}$ \\
\hline
\end{tabular}

To test the time complexity, this paper simulates variation of $m$ and $n$ value to know the algorithm's order of growth. Where $m$ is amount of criteria and $n$ is amount of alternative. 
Figure 3 shows algorithm's order of growth simulation. It simulates the value of $\mathrm{m}=3$, that means we have 3 criteria (distance, price and rating) and variation of $\mathrm{n}$ value (alternative or culinary menu) with $\mathrm{n}$ values range from 50, 75, 100 and 150. From figure 2, the AHP and fuzzy AHP order of growth is higher than AHP TOPSIS, it can concluded that AHP TOPSIS has the lowest time complexity from all methods compared.

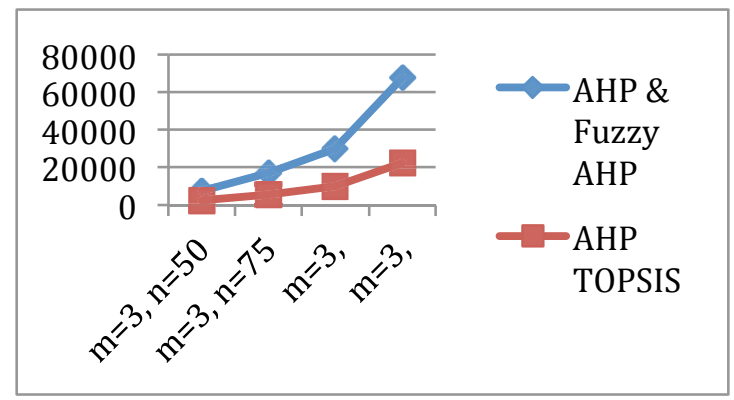

Fig. 3. Simulation in Order of Growth of Algorithms

\section{Conclusion}

Comparison was made based on accuracy and time complexity because mobile application environment needs low time complexity. The results have shown that all of these methods are suitable for culinary recommendation system in mobile environment. Fuzzy AHP have the highest accuracy between all of these methods, it have $66,67 \%$ accuracy. On the other hand, AHP TOPSIS shows the best performance in case of time complexity, with order of growth in quadratic class $\left(\mathrm{n}^{2}\right)$.

\section{$7 \quad$ References}

[1] Pinandito, A., C. P. Wulandari, and R. K. Dewi. "Culinary Recommendation System Using Analytical Hierarchy Process on Google Android Platform." International Conference on Engineering and Information Technology (ICEIT). 2015.

[2] Maharani, Septya, Heliza Rahmania Hatta, and Gery Merdiko. "Decision Support System of Culinary Recommendations using AHP and TOPSIS Methods with Map Visualization." Bali International Seminar on Science and Technology (BISSTECH) II. 2014.

[3] Nurrachman, R., Pinandito, A., R.K Dewi, "Implementasi Metode AHP TOPSIS pada Sistem Rekomendasi Kuliner.” Universitas Brawijaya, 2016.

[4] Pinandito, Aryo, et al. "Alternatives Weighting in Analytic Hierarchy Process of Mobile Culinary Recommendation System using Fuzzy", (2016).

[5] Levitin, Anany, and Soumen Mukherjee. "Introduction to the design \& analysis of algorithms". Reading: Addison-Wesley, 2003.

[6] Melvin, Alexander. "Decision-making using the analytic hierarchy process (AHP) and SAS/IML." SESUG, Paper SD-04 (2012). 
[7] Mamat, Nur Jumaadzan Zaleha, and Jacob Karikottu Daniel. "Statistical analyses on time complexity and rank consistency between singular value decomposition and the duality approach in AHP: A case study of faculty member selection." Mathematical and Computer Modelling 46.7 (2007): 1099-1106. https://doi.org/10.1016/j.mcm.2007.03.025

[8] Saaty, T. L. 1987. The Analytic Hierarchy Process -What It Is and How It Is Used. MathematicalModelling, Vol. 9, No. 3, pp.161-176. https://doi.org/10.1016/02700255(87)90473-8

[9] Saaty, Thomas L. "Decision making with the analytic hierarchy process." International journal of services sciences 1.1 (2008): 83-98. https://doi.org/10.1504/IJSSCI.2008.017590

[10] Shih, Hsu-Shih, Huan-Jyh Shyur, and E. Stanley Lee. "An extension of TOPSIS for group decision making." Mathematical and Computer Modelling 45.7 (2007): 801-813. https://doi.org/10.1016/j.mcm.2006.03.023

[11] Hamdani, and Retantyo Wardoyo. "The complexity calculation for group decision making using TOPSIS algorithm." AIP Conference Proceedings. Eds. Tri Rini Nuringtyas, et al. Vol. 1755. No. 1. AIP Publishing, 2016.

[12] Kilincci O. and Onal S. A. 201). Fuzzy AHP approach for supplier selection in a washing machine company.Expert Systems with Applications, Vol. 38, No. 8. pp.9656-9664. https://doi.org/10.1016/j.eswa.2011.01.159

[13] Hwang, C.L. and Yoon, K., Multiple attribute decision making: Methods and applications. New York: Springer-Verlag, (1981) https://doi.org/10.1007/978-3-642-48318-9

[14] Wegener, Ingo. Complexity theory: exploring the limits of efficient algorithms. Springer Science \& Business Media, 2005.

[15] Junior, Francisco Rodrigues Lima, Lauro Osiro, and Luiz Cesar Ribeiro Carpinetti. "A comparison between Fuzzy AHP and Fuzzy TOPSIS methods to supplier selection." Applied Soft Computing 21 (2014): 194-209. https://doi.org/10.1016/j.asoc.2014.03.014

\section{Authors}

Ratih Kartika Dewi is with the Multimedia, Game and Mobile Technology Research Group, Computer Science Department, Faculty of Computer Science, Brawijaya University, Malang - East Java, Indonesia (ratihkartikad@ub.ac.id).

Buce Trias Hanggara and Aryo Pinandito are with the Multimedia, Game and Mobile Technology Research Group, Information System Department, Faculty of Computer Science, Brawijaya University, Malang - East Java, Indonesia (bucetrias@gmail.com, aryo@ub.ac.id).

Article submitted 08 August 2017. Published as resubmitted by the authors 13 October 2017. 